LA W REN CE LIVERMORE N A TIONAL LABORATORY

\title{
Thermal annealing of laser damage precursors on fused silica surfaces
}

N. Shen, P. E. Miller, J. D. Bude, T. A. Laurence, T. I. Suratwala, W. A. Steele, M. D. Feit, L. L. Wang

March 20, 2012

Optics Express 
This document was prepared as an account of work sponsored by an agency of the United States government. Neither the United States government nor Lawrence Livermore National Security, LLC, nor any of their employees makes any warranty, expressed or implied, or assumes any legal liability or responsibility for the accuracy, completeness, or usefulness of any information, apparatus, product, or process disclosed, or represents that its use would not infringe privately owned rights. Reference herein to any specific commercial product, process, or service by trade name, trademark, manufacturer, or otherwise does not necessarily constitute or imply its endorsement, recommendation, or favoring by the United States government or Lawrence Livermore National Security, LLC. The views and opinions of authors expressed herein do not necessarily state or reflect those of the United States government or Lawrence Livermore National Security, LLC, and shall not be used for advertising or product endorsement purposes. 


\title{
Thermal annealing of laser damage precursors on fused silica surfaces
}

\author{
Nan Shen, Philip E. Miller, Jeff D. Bude, Ted A. Laurence, Tayyab I. Suratwala, \\ William A Steele, Michael D. Feit, and Lana L. Wong \\ Lawrence Livermore National Laboratory \\ 7000 East Ave., Livermore, CA 94550
}

\begin{abstract}
Previous studies have identified two significant precursors of laser damage on fused silica surfaces at fluenes below $\sim 35 \mathrm{~J} / \mathrm{cm}^{2}$, photoactive impurities in the polishing layer and surface fractures. In the present work, isothermal heating is studied as a means of remediating the highly absorptive, defect structure associated with surface fractures. A series of Vickers indentations were applied to silica surfaces at loads between $0.5 \mathrm{~N}$ and $10 \mathrm{~N}$ creating fracture networks between $\sim 10 \mu \mathrm{m}$ and $\sim 50 \mu \mathrm{m}$ in diameter. The indentations were characterized prior to and following thermal annealing under various time and temperature conditions using confocal timeresolved photo-luminescence (CTP) imaging, and R/1 optical damage testing with $3 \mathrm{~ns}, 355 \mathrm{~nm}$ laser pulses. Significant improvements in the damage thresholds, together with corresponding reductions in CTP intensity, were observed at temperatures well below the glass transition temperature $\left(\mathrm{T}_{\mathrm{g}}\right)$. For example, the damage threshold on $05 . \mathrm{N}$ indentations which typically initiates at fluences $<8 \mathrm{~J} / \mathrm{cm}^{2}$, could be improved $>35 \mathrm{~J} / \mathrm{cm}^{2}$ through the use of a $\sim 750{ }^{\circ} \mathrm{C}$ thermal treatment. Larger fracture networks required longer or higher temperature treatment to achieve similar results. At an annealing temperature $>1100^{\circ} \mathrm{C}$, optical microscopy indicates morphological changes in some of the fracture structure of indentations, although remnants of the original fracture and significant deformation was still observed after thermal annealing. This study demonstrates the potential of using isothermal annealing as a means of improving the laser damage resistance of fused silica optical components. Similarly, it provides a means of further understanding the physics associated with optical damage and related mitigation processes.
\end{abstract}




\section{INTRODUCTION}

There is a longstanding interest in the use of high average, high-peak power lasers in demanding applications such as inertial confinement fusion (ICF).[1-4] The peak power that can be sustained by such lasers is typically limited by the amount of self induced damage that can be tolerated by components making up the optical delivery system. All optical materials, including fused silica, have intrinsic absorption properties that will ultimately lead to damage at sufficiently high laser intensities. In practice, however, surface damage at fluences well below the intrinsic limit have been found to limit the performance of even the highest quality optical components.[5,6] These components can absorb photons with energies below the material band gap causing undesirable damage when exposed to high fluence light. There are a number of studies that have focused on indentifying the surface defects that may lead to such optical damage.[7-9] Recent studies[9] suggest that two sources of absorption exist which are primarily responsible for optically induced surface damage of fused silica optics exposed to ultraviolet wavelengths at fluence $<\approx 35 \mathrm{~J} / \mathrm{cm}^{2}$. These include absorption by photoactive impurities and by a thin layer of electronically defective material associated with even minute fractures on silica surfaces.

Moreover, our confocal time-resolved photo-luminescence microscopy (CTP) studies demonstrate the spatial coincidence between locations giving rise to a characteristic fast photoluminescent (FPL) signal and the locations at which optical damage occurs when subject to high fluence sub-band gap laser illumination. This useful diagnostic has led us to hypothesize that fracture surfaces generated during indentation processes[10] (including grinding, handling, intense laser irradiation etc.) create a region rich in defects. The photoluminescence (PL) 
observed from these fracture defects exhibits a broad distribution of lifetimes typically much shorter $(<1 \mathrm{~ns})$ than is observed from isolated point defects known to silica glass such as ODCs and NBOHCs (>>1 ns).[11-13] We hypothesize that the local density of defects is sufficiently high near fracture surfaces that they interact to form a quasi-continuum of electronic energy states, which results in fast PL and high absorptivity of sub band gap light. These states provide a means of transferring enough energy from the optical beam to the glass matrix to cause optical damage.

One widely applied method of removing point defects is to isothermally anneal the material in a furnace. Studies of defects induced by irradiation from neutrons or near-infrared femtosecond laser sources have shown that point defects in fused silica start to be annealed away at temperatures as low as $300^{\circ} \mathrm{C}$ and that the annealing process is accompanied by a significant reduction in photoluminescence $(\mathrm{PL})[14,15]$ signal. At temperatures of $\sim 500^{\circ} \mathrm{C}$, the $\mathrm{PL}$ characteristic of point defects almost disappears, indicating the reconstruction of broken $\mathrm{Si}-\mathrm{O}$ bonds generated during the initial irradiation.

This suggests that it may also be possible to anneal out the defects found to be associated with fractures that form the quasi-continuum states in fused silica. It would offer a possibility of improving the resistance of fused silica optics to optical surface damage. In this paper, we report experimental results of isothermal annealing on both the PL characteristics of fused silica and their corresponding laser damage propensity.

\section{EXPERIMENT}


Fractures with defects responsible for the sub-band gap absorption of light in fused silica can originate from optics fabrication steps, such as shaping or polishing operations. Alternately micro-scale fractures may be introduced as simple handling scratches or digs. In the present work we have used a Vickers indenter[16, 17] as a reproducible means of producing surface fractures on test specimens. The test substrates used in the present work were 2" diameter fused silica windows from CVI-Melles-Groit. Prior to indentation, samples were chemically leached to remove photoactive impurities[18] from the near surface of the optics. Indentation was performed using a Shimadzu Model HVM 2 micro-hardness tester, equipped with a Vickers indenter, using indentation loads ranging between $0.5 \mathrm{~N}$ and $10 \mathrm{~N}$. Such indentations resulted in the formation of fracture networks $\sim 10 \mu \mathrm{m}$ to $\sim 80 \mu \mathrm{m}$ in diameter and $\sim 1 \mu \mathrm{m}$ to $20 \mu \mathrm{m}$ depth as shown in Figure 1. Although not evident by optical microscopy, a more careful secondary electron microscopy (SEM) study revealed that small ( 20nm in width) fractures are present around the periphery of the plastically deformed zone[18] of even the $0.5 \mathrm{~N}$ indentations.

In addition to optical and secondary electron microscopy, indentations were characterized both before and after isothermal annealing using CTP imaging to look at the fast component $(\tau<5$ ns) of the photoluminescence (FPL) signal. This technique has been described in detail elsewhere[8]. Following indentation, samples were isothermally annealed in a furnace under a nitrogen atmosphere so that the reduction of damage precursors due to oxidation by oxygen in the ambient is minimized. The heating and cooling cycle was carefully controlled to minimize the possibility of introducing thermal stress into the glass by using a $5^{\circ} \mathrm{C} /$ minute heating rate and a $0.5^{\circ} \mathrm{C} /$ minute cooling rate. Using a series of samples, the annealing temperature was varied over a range from $750^{\circ} \mathrm{C}$ to $1150^{\circ} \mathrm{C}$ and the anneal time was varied from 3 to 96 hours. 
The damage propensity of the sample was assessed using small beam $\mathrm{R} / 1$ laser damage testing.[19] For optics with randomly distributed damage precursors, damage testing is typically performed using a centimeter-sized beam and reported as damage density as a function of laser fluence $\rho(\phi)$. The test results using small beams, on the other hand, may depend strongly on the beam size. In the present study, we used small beam $\mathrm{R} / 1$ damage testing as we are dealing with highly localized damage precursors. A second potential advantage of small beam damage testing is that one can target specific regions of the sample surface with spatial selectivity.

The small beam laser damage test in this study was performed using a Coherent Infinite Qswitched Nd:YAG laser operating at $355 \mathrm{~nm}$. The temporal profile of the laser pulse is Gaussian with pulse duration of $\sim 3 \mathrm{~ns}$. The laser is focused onto the indentation on the exit surface of the silica specimen using a long focal distance lens as shown in Figure 2. The laser pulse energy and its spatial profile are monitored by picking off a fraction of the beam and recording it using a charge coupled device (CCD) camera. The beam has a $1 / e^{2}$ spot size of $\sim 80 \mu \mathrm{m}$. An imaging microscope is set up to observe the sample under laser irradiation. During damage testing, the laser pulse energy is slowly ramped until damage is registered on the imaging CCD camera. In order to obtain an accurate measurement of the laser fluence, we cross register the laser spatial profile with the damage feature on the sample, and calculate the local fluence of the laser where the damage is observed.

\section{RESULTS}

In Figure 3, the damage initiation threshold, in the vicinity of a series of indentations applied at four different loads, is compared as a function of temperature for a fixed annealing 
time of 48 hours. The annealing temperatures used in the present work ranged between 750 and $1150^{\circ} \mathrm{C}$, and in all cases was kept below the thermal stress relief point $\left(\sim 1200^{\circ} \mathrm{C}\right)$ of the bulk glass to minimize potential distortions of the optical surfaces. As shown in Figure 3a, significant reduction in the FPL signal was observed for all the indentations at each temperature. The results of the FPL diagnostic were confirmed by the laser damage testing data summarized in Figure $3 b$. In particular, the results shown in Figure $3 b$ illustrate that the laser damage threshold following thermal annealing is a function of both the extent of fracturing initially present on the surface of the optic and the annealing temperature used. Smaller fracture networks, (i.e. fractures formed at lower indentation loads) and higher annealing temperatures typically resulted in higher optical damage thresholds. This suggests that the reconstruction of the defect layers on fracture surfaces that gives rise to sub-band gap absorbtivity is a thermally activated process which depends on the extent or severity of the initial fracture network. One can estimate the activation energy $\left(E_{a}\right)$ of the thermally driven rearrangement of the defect layer by fitting the temperature dependence of the damage threshold $(F)$ as a function of temperature $(T)$ according to an Arrhenius expression;

$$
F=F_{0} \exp \left(-E_{a} / R T\right)
$$

Table 1 summarizes the activation energy for the different indentation loads.

As one might expect, longer annealing times progressively reduced the FPL signal associated with fracture surfaces (see Figure 4a) and generally increased the damage threshold of the surface, until the threshold of the native surface is approached (Fig. 4b). 


\section{DISCUSSION}

A number of physical and mechanical "annealing" processes occur as a silicate glass is heated. We have attempted to summarize several of these processes in Figure 5. As shown in this Figure, only relatively modest temperatures $\left(\sim 400^{\circ} \mathrm{C}\right)$ and times are required to anneal out isolated point defects. As the density of defect states increases in indentation fractures, one would expect higher temperatures and/or longer times would be required to reconstruct the high density of defects that result in the formation of the quasi-continuum of electronic states responsible for sub-band gap absorption. As the temperature is raised further $\left(\sim 1200^{\circ} \mathrm{C}\right)$, mechanical stresses in the bulk material are relieved. Further heating results first in softening of the material and eventually in bulk material flow. The results presented here suggest that the reconstruction of the high density of defect states associated with indentation fractures can take place in a unique parameter space different from what results in stress relief or bulk flow (Figure 5). This implies that the annealing processes required to substantially increase the optical damage threshold of small surface imperfections on fused silica can be achieved through a judicious combination of temperature and annealing time. Such a method could, in principle, be used to treat any sized optic, provided heating and cooling is spatially uniform, while avoiding figure distortions that might compromise the optical properties of the component.

As the annealing temperature approaches that required to relieve mechanical stress $\left(\sim 1200^{\circ} \mathrm{C}\right)$, one begins to observe the partial healing or closing the smaller fractures (micrometer or less) whose surfaces are in close proximity to one another (Fig. 6). Similar behavior was not observed on larger fractures. This could be expected[20] as temperature approaches the glass transition temperature since the characteristic time to heal a feature of size $\mathrm{L}$ is $\mu \mathrm{L} / \sigma$ where $\mu$ is the viscosity and $\sigma$ the surface tension. Since silica viscosity is an exponential function of 
temperature, the size of features that can be closed is expected to vary exponentially with annealing temperature.

This suggests that the proximity of the two surfaces may be of importance during the thermally mitigated reconstruction of the defect structure that underlies optical damage. Alternately, the thermally driven increase in laser damage threshold, reported here, may be the result of strictly a surface diffusion phenomenon, which does not require the close proximity of a mating surface. To explore this question we used the direct cleavage double compression (DCDC) method to grow a matching pair of isolated fracture surfaces.[9, 21] Surprisingly, unlike indentation fractures, very little FPL signal was observed on the fracture surfaces produced using the DCDC technique. The high damage threshold of the fractures produced using the DCDC method was similar to that of a fracture free polished surface. The fracture surfaces created during the DCDC experiment are produced under pure tensile stress conditions at or near the critical stress intensity. Fractures formed during indentation and during laser damage are presumably created much more violently and under conditions of much higher stress intensity. These differences likely result in a significant difference in the population of electronic defects states remaining on surfaces following macroscopic fracture. Further study is presently underway to better understand both the origin and population of defects associated with fracture surfaces, and to develop more effective strategies to improve optics performance.

\section{CONCLUSION}

In the absence of photoactive impurities in the polishing layer, thermal processes, even at temperatures well below that required to relive mechanical stresses, have been demonstrated to 
reduce FPL defects and improve the UV laser damage threshold of fracture defects on fused silica surfaces. We attribute this behavior to a reduction in the population of electronic defects states that are formed on fracture surfaces during violent processes, such as indentation. It remains unclear if the reduction in defect population evidenced by both the observed reduction on FPL intensity and increase in local damage threshold are the result of surface diffusion or require the presence of a mating surface in close proximity.

\section{ACKNOWLEDGMENTS}

This work performed under the auspices of the U.S. Department of Energy by Lawrence Livermore National Laboratory under Contract DE-AC52-07NA27344.

1. T. C. Sangster, R. L. McCrory, V. N. Goncharov, D. R. Harding, S. J. Loucks, P. W. McKenty, D. D. Meyerhofer, S. Skupsky, B. Yaakobi, B. J. MacGowan, L. J. Atherton, B. A. Hammel, J. D. Lindl, E. I. Moses, J. L. Porter, M. E. Cuneo, M. K. Matzen, C. W. Barnes, J. C. Fernandez, D. C. Wilson, J. D. Kilkenny, T. P. Bernat, A. Nikroo, B. G. Logan, S. Yu, R. D. Petrasso, J. D. Sethian, and S. Obenschain, "Overview of inertial fusion research in the United States," Nucl. Fusion 47(10), S686-S695 (2007).

2. J. Caird, V. Agrawal, A. Bayramian, R. Beach, J. Britten, D. Chen, R. Cross, C. Ebbers, A. Erlandson, M. Feit, B. Freitas, C. Ghosh, C. Haefner, D. Homoelle, T. Ladran, J. Latkowski, W. Molander, J. Murray, S. Rubenchik, K. Schaffers, C. Siders, E. Stappaerts, S. Sutton, S. Telford, J. Trenholme, and C. Barty, "Nd:GLASS LASER DESIGN FOR LASER ICF FISSION ENERGY (LIFE)," Fusion Sci. Technol. 56(2), 607-617 (2009).

3. J. Lindl, "Development of the indirect-drive approach to inertial confinement fusion and the target physics basis for ignition and gain," Phys. Plasma 2, 3933 (1995).

4. J. Nuckolls, A. Thiessen, L. Wood, and Zimmerma.G, "Laser Compression of Matter to Super-High Densities - Thermonuclear (Ctr) Applications," Nature 239(5368), 139-\& (1972).

5. S. C. Jones, P. Braunlich, R. T. Casper, X. A. Shen, and P. Kelly, "Recent Progress on Laser-Induced Modifications and Intrinsic Bulk Damage of Wide-Gap OpticalMaterials," Opt. Eng. 28(10), 1039-1068 (1989).

6. B. C. Stuart, M. D. Feit, S. Herman, A. M. Rubenchik, B. W. Shore, and M. D. Perry, "Optical ablation by high-power short-pulse lasers," J. Opt. Soc. Am. B 13(2), 459-468 (1996). 
7. J. Bude, G. Guss, M. Matthews, and M. L. Spaeth, "The effect of lattice temperature on surface damage in fused silica optics," in Laser-Induced Damage in Optical Materials:2007 (2007), p. 672009.

8. T. A. Laurence, J. D. Bude, N. Shen, T. Feldman, P. E. Miller, W. A. Steele, and T. Suratwala, "Metallic-like photoluminescence and absorption in fused silica surface flaws," Appl. Phys. Lett. 94(15)(2009).

9. P. E. Miller, J. D. Bude, T. I. Suratwala, N. Shen, T. A. Laurence, W. A. Steele, J. Menapace, M. D. Feit, and L. L. Wong, "Fracture Incuded Sub-Band Gap Absorption as a Precursor to Optical Damage on fused Silica Surfaces," Opt. Lett. 35(16), 2702-2704 (2010).

10. B. Lawn and R. Wilshaw, "Indentation Fracture - Principles and Applications," J. Mater. Sci. 10(6), 1049-1081 (1975).

11. G. Pacchioni, L. Skuja, and D. L. Griscom, Defects in SiO2 and Related Dielectrics: Science and Technology (Kluwer, Dordrecht, Netherlands, 2000).

12. L. Skuja, "The Origin of the Intrinsic 1.9 Ev Luminescence Band in Glassy Sio2," $J$. Non-Cryst. Solids 179, 51-69 (1994).

13. L. Skuja, "Optically active oxygen-deficiency-related centers in amorphous silicon dioxide," J. Non-Cryst. Solids 239(1-3), 16-48 (1998).

14. J. F. Latkowski, A. Kubota, M. J. Caturla, S. N. Dixit, J. A. Speth, and S. A. Payne, "Fused silica final optics for inertial fusion energy: Radiation studies and system-level analysis," Fusion Sci. Technol. 43(4), 540-558 (2003).

15. H. B. Sun, S. Juodkazis, M. Watanabe, S. Matsuo, H. Misawa, and J. Nishii, "Generation and recombination of defects in vitreous silica induced by irradiation with a near-infrared femtosecond laser," J. Phys. Chem. B 104(15), 3450-3455 (2000).

16. C. Janssen, "Specimen for Fracture Mechanics Studies on Glass," Rev. Phys. Appl. 12(5), 803-803 (1977).

17. R. L. Smith and G. E. Sandland, "An Accurate Method of Determining the Hardness of Metals, with Particular Reference to Those of a High Degree of Hardness," Proc. Inst. Mech. Eng. 1, 623-641 (1922).

18. P. E. Miller, T. I. Suratwala, J. D. Bude, T. A. Laurence, N. Shen, W. A. Steele, M. D. Feit, J. A. Menapace, and L. L. Wang, "Laser damage precursors in fused silica," Proc. Soc. Photo-opt. Inst. Eng. 7504, 75040X (2009).

19. J. Hue, P. Carrec, J. Dijon, and P. Lyan, "R-on-1 Automatic Mapping: a New Tool for Laser Damage Testing," in Laser-Induced Damage in Optical Materials (1996), pp. 90100.

20. M. D. Feit and A. M. Rubenchik, "Mechanisms Of CO2 laser mitigation of laser damage growth in fused silica," in Laser-Induced Damage in Optical Materials: 2002 and 7th International Workshop on Laser Beam and Optics Characterization (2002), pp. 91-102.

21. S. N. Crichton, M. Tomozawa, J. S. Hayden, T. I. Suratwala, and J. H. Campbell, "Subcritical crack growth in a phosphate laser glass," J. Am. Ceram. Soc. 82(11), 30973104 (1999). 


\section{TABLE}

Table I. Activation energy of the thermal reconstruction of fracture defects.

\begin{tabular}{|c|c|}
\hline Indent Load $(\mathrm{N})$ & Activation Energy $(\mathrm{kJ} / \mathrm{mol})$ \\
\hline 0.5 & 7.9 \\
\hline 2 & 21.3 \\
\hline 5 & 51.2 \\
\hline 10 & 56.2 \\
\hline
\end{tabular}

\section{FIGURE CAPTIONS}

Figure 1. Optical microscopy images of Vickers indentations at different loads.

Figure 2. Schematic of the small beam R/1 laser damage testing setup.

Figure 3. Temperature dependent isothermal annealing and fast PL characteristics. (a) Fast PL decreases from indentations as the result of annealing at $1150^{\circ} \mathrm{C}$, and (b) damage performance improves.

Figure 4. Time dependent isothermal anneal. (a) Fast PL reduces significantly as the annealing time increases, and (b) damage threshold increases especially for smaller load indentations.

Figure 5. Thermal processes occur in silica glass.

Figure 6. Partial fracture healing/closing during isothermal annealing of fracture defects. 


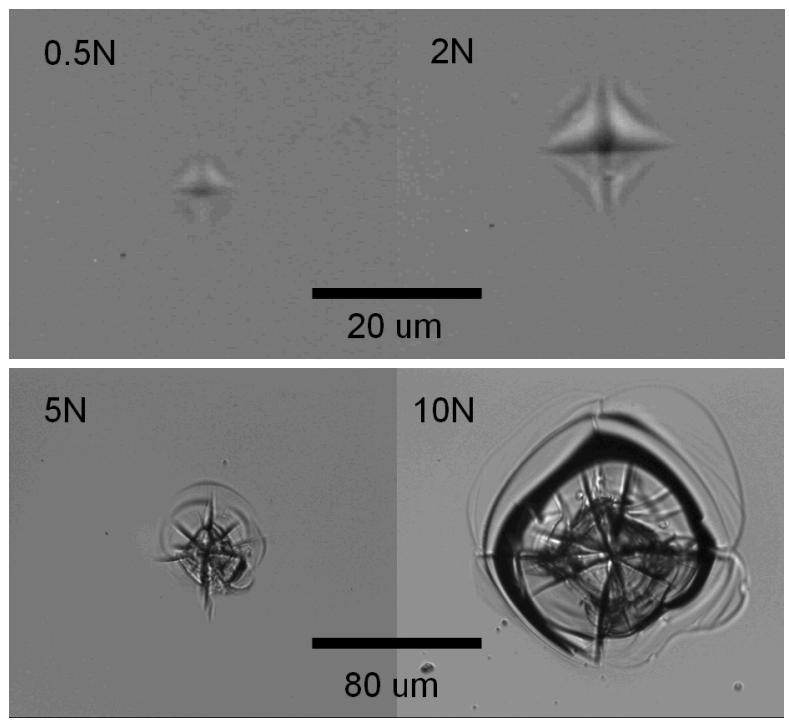

Figure 1 

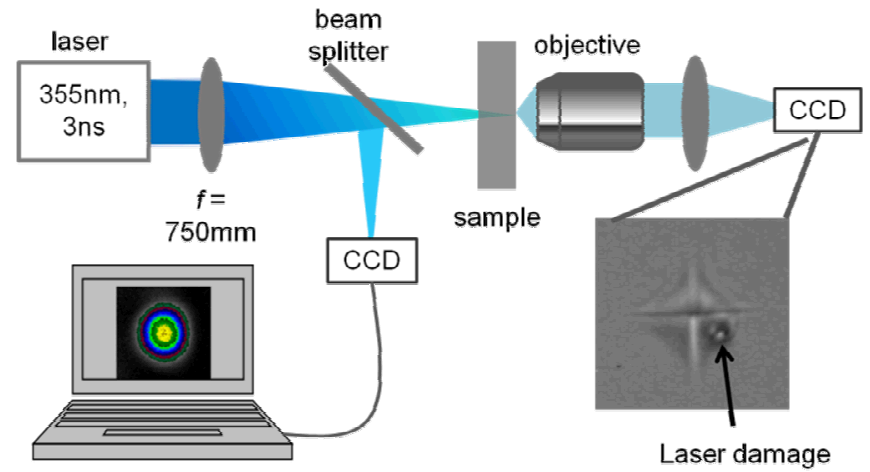

Figure 2 
(a)

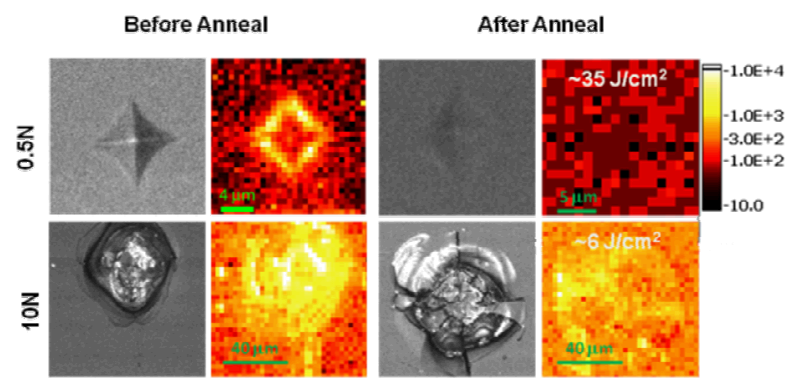

(b)

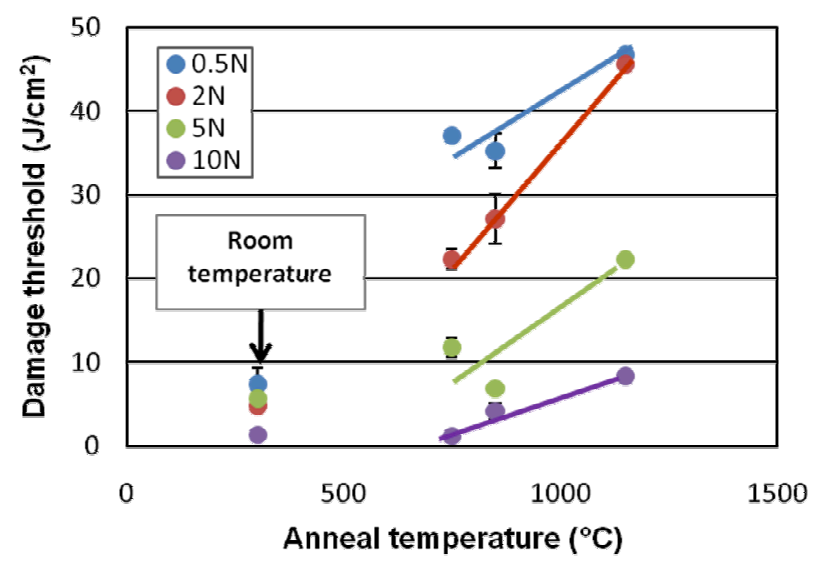

Figure 3 
(a)

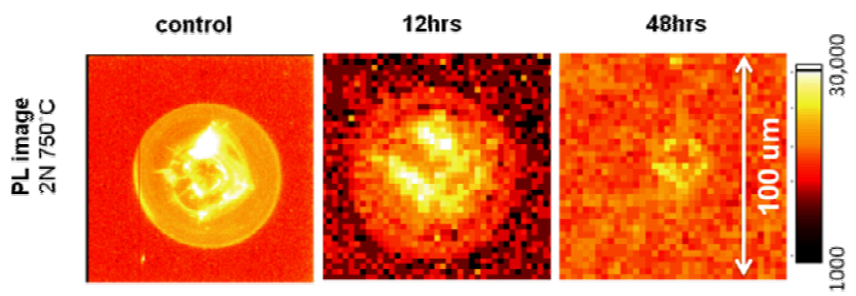

(b)

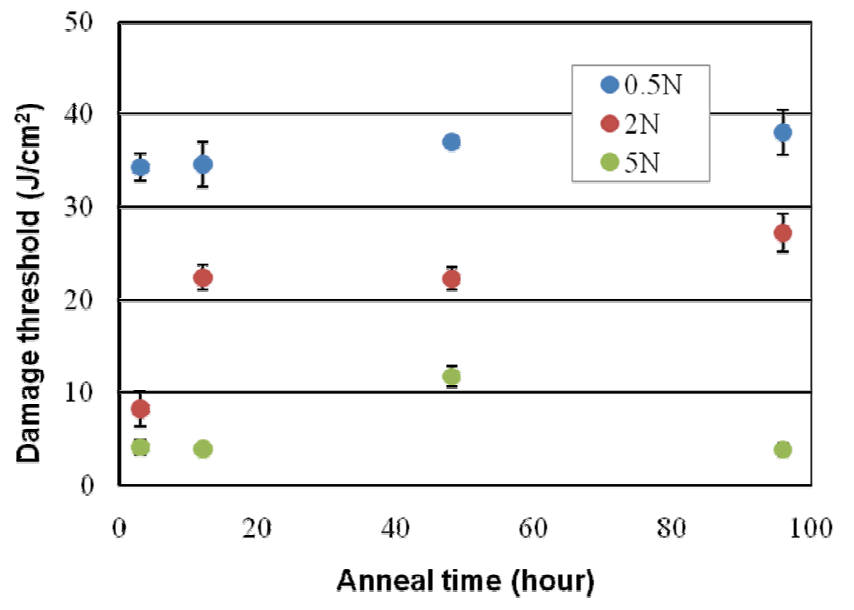

Figure 4 


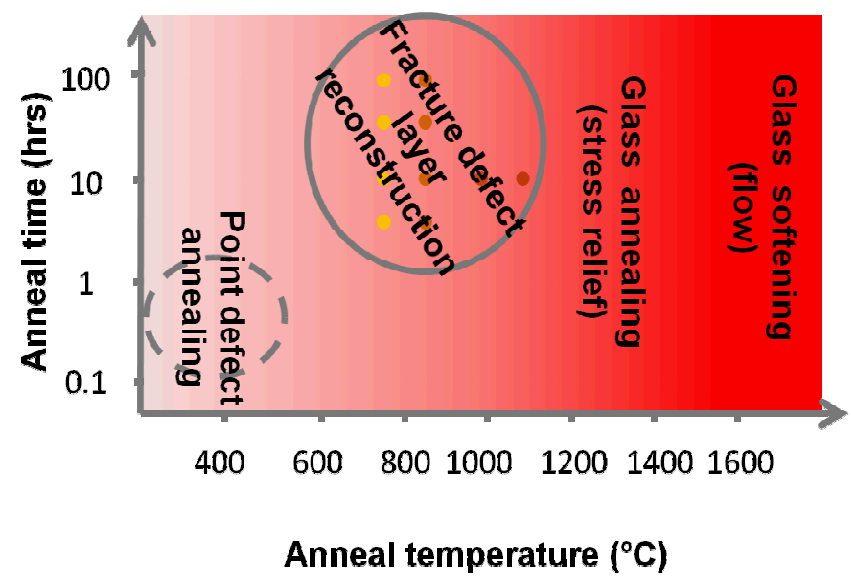

Figure 5 

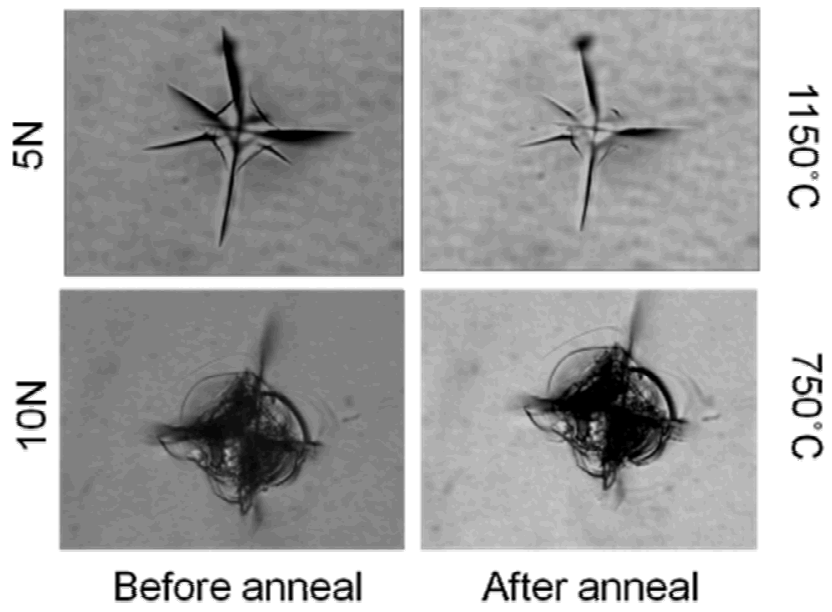

Before anneal

After annea

Figure 6 